\title{
Curso de Pedagogia no Brasil: História e Formação com Pedagogos Primordiais
}

GISELI BARRETO DA CRUZ

RIO DE JANEIRO: WAK EDITORA, 2011, 218 p.

O livro é fruto da pesquisa de doutorado da autora, que aborda a história do curso de Pedagogia no Brasil, basicamente por meio da análise dos depoimentos de Pedagogos brasileiros e da legislação oficial que regulamentou o curso durante sua trajetória. A questão central foi saber como se posicionavam aqueles pedagogos que foram testemunhas dos tempos iniciais de implantação do curso no país. A pesquisa esteve voltada para os depoimentos dos que obtiveram formação em Pedagogia desde 1939 - ano de criação e implantação do curso - até 1969 - quando foi homologado o parecer 252/69, que imprimiu mudanças significativas na composição curricular do curso. A autora trabalhou com os depoimentos de 17 pedagogos formados nas décadas de 1940, 1950 e 1960, sendo 9 formados em instituições públicas e 8 , em instituições privadas do país.

A escolha dos sujeitos foi fundamental para definir a composição de um grupo representativo que vivenciou a fase inicial do curso. Tais pedagogos foram definidos pela autora como "primordiais", pela dupla condição apresentada: por terem vivenciado a fase de implantação do curso como alunos de graduação em Pedagogia, e por terem se consolidado na área de educação como formadores e pesquisadores, mantendo-se atuantes e influentes desde então ${ }^{1}$. Apenas um dos entrevistados não possui graduação em Pedagogia, mas seu depoimento não poderia deixar de compor o quadro pretendido para

O grupo de pedagogos entrevistados é formado por 14 mulheres e 3 homens, sendo eles: Alda Junqueira Marin, Amélia Americano Domingues de Castro, Bernardete Angelina Gatti, Carmem Silvia Bissoli da Silva, Celestino Alves da Silva Júnior, Célia Frazão Soares Linhares, Eulina Fontoura de Carvalho, IIma Passos Alencastro Veiga, Jorge Nagle, José Cerchi Fusari, Leonor Maria Tanuri, Maria Amélia Santoro Franco, Maria Aparecida Forest Ferreira da Costa, Marlene Alves de Oliveira Carvalho, Selma Garrido Pimenta, Vera Maria Candau e Vera Maria Nigro de Souza Placco. 
a pesquisa pelo fato de ter vivido de perto os anos iniciais de formação do curso como integrante do corpo docente da Faculdade de Filosofia, Ciências e Letras da Universidade de São Paulo - FFCL/USP.

A autora destaca que a maioria dos entrevistados exerceu, em algum momento de sua trajetória profissional, funções referentes ao ofício de pedagogo, tais como: inspetor de ensino na esfera federal; técnico de planejamento; curriculista no contexto dos sistemas estadual e federal; diretor, coordenador pedagógico ou orientador educacional.

Com base na questão central da pesquisa, o roteiro para a realização das entrevistas semiestruturadas seguiu alguns eixos de análise: trajetória de formação e atuação; trajetória de estudante no curso de Pedagogia; trajetória de pedagogo, de formador e de pesquisador; e posições defendidas sobre a Pedagogia, a fim de discutir a natureza dos conhecimentos e sua materialização no curso. O referencial teórico adotado foi diverso e plural, “tal como é diversa e plural a Pedagogia” (p. 26).

O livro é apresentado em quatro capítulos. No capítulo 1, “O curso de Pedagogia no Brasil: uma revisão histórica”, a autora apresentou alguns traços da trajetória do curso de Pedagogia no país a fim de situar historicamente a discussão, porém a autora esclarece que não se propõe a fazer uma pesquisa histórica acerca da formação docente. Para isso, ela faz uma discussão sobre quatro marcos legais que regulamentaram a trajetória do curso de Pedagogia.

O primeiro marco data de 1939, quando o governo federal promulgou o decreto-lei n. 1.190/39, criando o curso de Pedagogia ao organizar a Faculdade Nacional de Filosofia - FNFi. Os anos de 1930 foram marcados por importantes iniciativas no campo educacional, dentre elas o trabalho desenvolvido pelos institutos de educação, tendo como base as experiências escolanovistas. A autora aborda o papel dos institutos de educação para justificar que a Pedagogia já fazia parte do contexto universitário antes mesmo de constituir um curso. Ao ser criado, o curso visava à formação de bacharéis em Pedagogia para ocuparem os cargos técnicos em educação, fato que representou, conforme sua opinião, uma distorção da própria concepção da FFCL, uma vez que sua função seria a de formar "um núcleo de pesquisas não profissionais, voltado especificamente para a formação cultural e específica, por meio dos estudos históricos, filosóficos e sociológicos, principalmente" (p. 36). Quando licenciado, o pedagogo poderia lecionar nas escolas normais, instituições responsáveis pela formação de professores primários. Dessa forma, os cursos de Pedagogia passaram a ser objeto de disputa - para a formação do professor primário - e de crítica - devido à sua natureza e função.

O segundo marco data de 1962, com a aprovação do parecer CFE 251/62, estabelecendo novo currículo mínimo e nova duração para o curso. Apesar da reformulação, o curso manteve a dualidade bacharelado versus licenciatura. 
O terceiro marco data de 1969, com a aprovação do parecer CFE 252/69, que veio acompanhado da resolução CFE n. 2/1969, novamente instituindo um currículo mínimo e outra duração para o curso. A partir de então, o curso de Pedagogia foi fracionado em habilitações técnicas, formando especialistas voltados aos trabalhos de planejamento, supervisão, administração e orientação educacional. Tais habilitações passaram a definir o perfil profissional do pedagogo. A Didática tornou-se disciplina obrigatória, sendo, antes, um curso realizado à parte para se obter a licença para o magistério. A Reforma Universitária de 1968 (lei n. 5.540/68) trouxe mudança significativa para o curso de Pedagogia, que deixou de fazer parte da Faculdade de Filosofia para integrar a Faculdade de Educação, instituída pela reforma. Essa fragmentação do trabalho pedagógico gerou inúmeras críticas desde os anos de 1970, desencadeando um movimento de reformulação dos cursos de Pedagogia nos anos de 1980, com o amparo da Associação Nacional pela Formação dos Profissionais da Educação - Anfope. Esta obteve o aval do Conselho Federal de Educação - CFE -, que passou a aceitar propostas alternativas ao disposto no terceiro marco legal. Com isso, "muitas instituições, progressivamente, foram incorporando novas habilitações ao Curso de Pedagogia, voltadas essencialmente para a docência” (p. 50).

No quarto marco, é abordada a resolução CNE n. 1, de 10/4/2006, que fixou diretrizes curriculares, inaugurando nova fase para o curso no que diz respeito à formação dos profissionais da educação. O pedagogo passa a assumir o perfil de um profissional capacitado para atuar no ensino, na organização e na gestão do trabalho pedagógico em diferentes contextos educacionais.

A partir do segundo capítulo, a autora se dedica essencialmente à analise dos depoimentos. No capítulo 2, "Trajetórias e memórias de pedagogos primordiais: os primórdios do curso de Pedagogia no Brasil”, enfatiza a forte relação parental entre o curso normal e o curso de Pedagogia. Em todos os depoimentos, há fortes indícios de que o curso de Pedagogia se firmou como uma continuidade natural do curso normal, uma vez que o trabalho desenvolvido na escola normal foi nele se consolidando, pois os professores que lecionavam nas escolas normais - não pedagogos, com formações diversas vieram a compor os quadros docentes dos cursos de Pedagogia. Para a grande maioria dos entrevistados, o curso normal era o meio para se obter a formação docente, enquanto o curso de Pedagogia - além de formar professor para o curso ginasial e para a escola normal - não explorava suficientemente esse ofício. Isto é, o curso de Pedagogia, por fornecer uma sólida formação teórica, foi fundamental para o processo de formar o "pensador" da educação. Os depoimentos também apresentam: um curso de Pedagogia desvinculado da realidade escolar; uma ênfase na abrangência da Pedagogia, amparada por diferentes áreas disciplinares; a multiplicidade teórica do curso; a centralida- 
de nos estudos clássicos de educação; uma bibliografia predominantemente estrangeira, exigindo um domínio de diferentes línguas por parte dos alunos; a criação do hábito de estudos em grupo; curso tradicional, marcado exclusivamente pelo predomínio de aulas expositivas, trabalhos de interpretação de texto e provas de arguição oral; a forte presença da pesquisa no curso, tanto no sentido de impulsionar investigações científicas no país quanto a formação de pesquisadores.

No capítulo 3, "Trajetórias e memórias de pedagogos primordiais: relatos sobre o curso de Pedagogia no Brasil”, a autora se refere ao ambiente altamente politizado que os estudantes do curso de Pedagogia frequentaram nos anos de 1960. Em muitos casos, esse clima teria sido mais determinante do que a cultura específica da sala de aula. Para grande parte dos entrevistados, o ambiente acadêmico, a cultura universitária e, principalmente, o movimento estudantil foram meios diferenciais na sua formação, sendo que grande parte deles frequentou o curso entre os anos de 1958 e 1968, década de forte efervescência política no país.

São posteriormente apresentados os diferenciais entre o curso de que esses sujeitos fizeram parte como estudantes e o curso em que atuaram como formadores. Segundo a autora, a perda da densidade teórica constituiu característica básica na visão desses pedagogos ao atuarem como formadores. Além disso, destacam-se também o papel secundarizado dos estudos clássicos em educação, a dificuldade de construção de sínteses e o baixo capital cultural dos alunos. Apenas uma entrevistada vê os anos de 1980 como um período frutífero devido, principalmente, ao surgimento de uma literatura predominantemente brasileira e de caráter progressista.

Em um terceiro momento, são discutidas as significativas mudanças que a Reforma Universitária de 1968 imprimiu ao sistema de ensino superior, principalmente com as implicações do terceiro marco (parecer CFE n. 252/69), que introduziu as habilitações técnicas no curso de Pedagogia, fracionando a formação do pedagogo em especializações. No tocante às habilitações, os entrevistados questionam o seu papel no currículo, embora admitam que tais habilitações buscaram imprimir no curso os possíveis papéis que um pedagogo deveria assumir. Ao mesmo tempo em que possibilitou outras frentes de atuação, o curso tornou-se disperso diante das diversas possibilidades formativas, demandando a produção de um corpus teórico que fundamentasse as habilitações.

Finalmente, a autora se dispõe a desvelar a visão dos entrevistados sobre as diretrizes curriculares de 2006 do curso de Pedagogia. Se ao longo de sua trajetória, o curso esteve afastado da escola primária, agora as relações com esta se estreitam. Ele passa a ser a instância responsável pela formação de professores, tendendo a assumir o perfil de um curso normal superior. A 
análise das entrevistas aponta três aspectos relevantes: o afastamento da teoria - diante da diversidade de temas propostos - gerando fragmentação do curso devido ao excesso de disciplinas; o não-lugar das habilitações, uma vez que a formação do pedagogo se volta para a docência, embora permaneça o ofício designado pelas habilitações; e a docência como base da formação do pedagogo. Os entrevistados consideram que a docência é necessária ao trabalho do pedagogo, mas não somente ela, expressando o receio de se secundarizar a própria Pedagogia. Nesse sentido, os pedagogos primordiais percebem nas diretrizes curriculares de 2006 um esvaziamento do que é próprio da Pedagogia.

No capítulo 4, "Concepções de pedagogos primordiais: a posição do curso de Pedagogia no contexto do campo acadêmico”, a intenção é analisar como esse grupo de pedagogos situa o curso de Pedagogia no contexto do campo acadêmico e como entende a Pedagogia como área de conhecimento. Segundo a autora, situá-la como ciência da Educação ainda é um ponto muito questionável, uma vez que os entrevistados possuem posicionamentos diversos: para alguns, a Pedagogia é uma ciência; para outros, é algo insuficientemente definido; para outros ela precisa ser ciência para se tornar legítima.

Quanto ao contexto acadêmico, a autora entende que, apesar de a Pedagogia teorizar sobre a educação, as diferentes áreas das ciências humanas também contribuem para isso. Ela apresenta porém um diferencial em relação às demais áreas, que é o objetivo de formulação de diretrizes para a prática educativa.

O desenvolvimento da pós-graduação no Brasil também é fator de destaque nos depoimentos. Para os entrevistados, a pós-graduação contribuiu substancialmente para a construção da pesquisa em educação no Brasil, fazendo crescer o corpo teórico sobre a área educacional, porém tal fato não representou um avanço para o curso de Pedagogia. Boa parte dos entrevistados cursou pós-graduação no exterior, impulsionando a criação e o desenvolvimento dos programas de pós-graduação em educação por todo o país. As ideias pedagógicas alcançaram maior circularidade a partir dos anos de 1980, aumentando a produção acadêmico-científica por meio da pós-graduação. Se, por um lado, a pós-graduação favoreceu a formação qualificada de docentes para o curso de Pedagogia, por outro, os problemas da prática pedagógica não têm sido suficientemente explorados nas pesquisas, e a falta de continuidade nas investigações é apontada como um problema.

Ao concluir, a autora afirma que, apesar de a Pedagogia se apresentar fragilizada diante de outras áreas de conhecimento, ela é uma área que comunga dos saberes interdisciplinares, possuindo uma dimensão plural e assimétrica na relação entre a Filosofia e a ciência, e na relação teoria e prática.

Recomendo a leitura desta publicação, pois ela apresenta importante contribuição para a área educacional e, especialmente, para o campo da 
história da educação brasileira por contemplar a história do curso de Pedagogia no Brasil por meio dos depoimentos de pedagogos que vivenciaram os primórdios desse curso, seja pela vivência como alunos, seja pela fecunda contribuição de seus trabalhos, mantendo-se influentes e atuantes como formadores e pesquisadores na área educacional.

VIVIANE LOVATTI FERREIRA

Pós-Doutoranda do Programa de Estudos Pós-Graduados em Educação Matemática da Pontifícia Universidade Católica de São Paulo - PUC-SP vlovatti@usp.br 